\title{
Soluble CD40 ligand inhibits the growth of non-Hodgkin's lymphoma cells through the JNK signaling pathway
}

\author{
ZHONGXIN FENG ${ }^{1-3}$ and JISHI WANG ${ }^{1-3}$ \\ ${ }^{1}$ Department of Clinical Medical School, Guizhou Medical University; ${ }^{2}$ Department of Hematology, Affiliated Hospital of \\ Guizhou Medical University; ${ }^{3}$ Department of Guizhou Province Hematopoietic Stem Cell Transplantation Center and \\ Key Laboratory of Hematological Disease Diagnostic and Treatment Centre, Guiyang, Guizhou 550004, P.R. China
}

Received June 9, 2020; Accepted October 21, 2020

DOI: $10.3892 / 01.2020 .12318$

\begin{abstract}
The incidence of non-Hodgkin's lymphoma (NHL) has been increasing annually and has become a serious threat to human health. However, the pathogenesis of NHL remains unclear. The present study aimed to investigate the effect of soluble CD40 ligand (sCD40L) on NHL cells and its underlying mechanism. Cell Counting kit-8 assay and flow cytometry apoptosis experiments were conducted to investigate the effects of $\mathrm{sCD} 40 \mathrm{~L}$ on cell proliferation and apoptosis. Western blotting was performed to detect the protein expression levels of BAX, Bcl-2, ERK, p-ERK, JNK, p-JNK, p38, p-p38 and c-JUN. The results of the present study demonstrated that exogenous SCD40L significantly inhibited the proliferation and promoted the apoptosis of Raji and CA46 cells. Additionally, exogenous sCD40L promoted the apoptosis of lymphoma cells by activating the JNK signaling pathway.
\end{abstract}

\section{Introduction}

Malignant lymphoma (ML), a type of hematological malignancy, occurs in the lymph nodes or lymphoid tissues outside the lymph nodes (1). Non-Hodgkin's lymphoma (NHL) is the most common type of lymphoma and is about $4 \%$ of all cancers in the United States (2). Approximately $85-90 \%$ of all NHL cases are of B cell origin (3). The incidence rate of lymphoma continues to increase globally, causing serious harm to human health (3). However, the pathogenesis of NHL remains unclear.

Correspondence to: Professor Jishi Wang, Department of Hematology, Affiliated Hospital of Guizhou Medical University, 9 Beijing Street, Yunyan, Guiyang, Guizhou 550004, P.R. China E-mail: wangjishi9646@163.com

Abbreviations: c-JUN, oncoprotein c-JUN; ML, malignant lymphoma; NHL, non-Hodgkin's lymphoma; p38, p38 mitogenactivated protein kinases; p-ERK, phosphorylated ERK; p-JNK, phosphorylated JNK; p-p38, phosphorylated p38; sCD40L, soluble CD40 ligand

Key words: sCD40L, Raji, CA46, proliferation, JNK, non-Hodgkin's lymphoma
CD40, a 48-kDa type 1 transmembrane cell surface receptor, was initially identified in B lymphocytes and was found to trigger numerous key processes (4). CD40 is a member of the tumor necrosis factor (TNF) receptor superfamily and is widely expressed in several hematological cancer types and solid tumors, including leukemias (5), gastric cancer and bladder cancer $(6,7)$. The natural ligand of the CD40 receptor is CD40L, also known as CD154 or gp39, which belongs to the TNF family and is a type II transmembrane protein with a relative molecular mass of $39 \mathrm{kDa}$. In the 1990s, Mach et al (8) demonstrated that atheroma of mice treated with anti-CD40L antibody contained significantly fewer macrophages $(64 \%)$ and $\mathrm{T}$ lymphocytes (70\%) and exhibited decreased expression of vascular cell adhesion molecule-1. This indicated that CD40 served an important role in atherogenesis (8). Additionally, membrane-bound CD40L may promote senescence and initiate senescence-associated secretory phenotype via $\mathrm{NF}-\kappa \mathrm{B}$ activation in lung adenocarcinoma (9). Activated CD40, through CD40L, serves a central role in regulating the proliferation of CD4 (+) and CD8 (+) T cells, as well as $\mathrm{T}$ cell and $\mathrm{B}$ cell activity (10-12). Under certain conditions, CD40L may bind to the receptor protein CD40 on the surface of tumor cells, thereby activating the CD40 relative downstream signaling pathway to regulate the proliferation of tumor cells (13). The suppression of CD40L expression in $\mathrm{T}$ cells has also been demonstrated in B cell chronic lymphocytic leukemia (14). Our previous study demonstrated that the upregulation of CD40L expression attenuated drug resistance in Adriamycin-resistant THP-1 cells (15). Furthermore, recent studies have demonstrated that CD40L may significantly inhibit the cell proliferation and promote the cell apoptosis of cancer cells, including colon cancer and ovarian cancer cells $(16,17)$. A previous study reported that CD40 may induce apoptosis of carcinoma cells through a mechanism involving TRAF3 and JNK/AP-1 activation (18). At present, the effect of CD40L on tumors has become a popular topic in the field of tumor pathogenesis (19-21). Additionally, CD40 activation has anti-apoptotic or apoptotic effects in follicular lymphoma (FL) cell lines (PMID: 28610909) (22). However, the function and mechanism of CD40/CD40L in NHL are rarely reported.

In the present study, the NHL cells were treated with soluble CD40 ligand (sCD40L). By conducting Cell Counting kit-8 (CCK-8) assays, cell flow cytometry and western blot 
analysis, the present study confirmed that exogenous CD40L inhibited the proliferation and promoted the apoptosis of NHL cells by activating the JNK signaling pathway. The present study serves as a basis for examining CD40L in the clinical treatment of NHL.

\section{Materials and methods}

Cells and reagents. Human Burkitt lymphoma (NHL) Raji (no. bncc338283) and CA46 (no. bncc337642) cell lines were purchased from BeNa Culture Collection. Antibodies against Bax (cat. no. SC-7480) and Bcl-2 (cat. no. SC-7382) were purchased from Santa Cruz Biotechnology, lnc. Antibodies against ERK (cat. no. 4695T), p-ERK (cat. no. 4370T), p38 (cat. no. 8690T), p-p38 (cat. no. 4511S), JNK (cat. no. 9252T), p-JNK (cat. no. 9255S), c-JUN (cat. no. 9165T) and GAPDH (cat. no. 5174T) were purchased from CST Biological Reagents Co., Ltd. CCK-8 kit (kit no. C0037) was purchased from Beyotime Institute of Biotechnology. sCD40L (no. cyt-245) was purchased from Prospec-Tany TechnoGene, Ltd. JNK inhibitor SP600125 was purchased from Selleck Chemicals.

CCK- 8 assay. Cells were cultured in RPIM-1640 medium (SH30809.01; Hyclone; GE Healthcare Life Sciences) which supplemented with $10 \%$ fetal bovine serum (cat. no. 900-108; Gemini Bio Products) in a cell incubator $\left(5 \% \mathrm{CO}_{2}, 37^{\circ} \mathrm{C}\right)$. When the confluence of the cells reached $95 \%$, the cells were digested, collected and resuspended in PRIM-1640 medium. The cells were then transferred onto 96 -well plates $\left(5 \times 10^{4}\right.$ cells/well $)$. Following incubation for $24 \mathrm{~h}$, the cells were further treated with different concentrations of $\operatorname{sCD} 40 \mathrm{~L}(0,2,4,6,8$ and $10 \mu \mathrm{g} / \mathrm{ml}$ ) for $48 \mathrm{~h}$ or $10 \mu \mathrm{mol} / 1 \mathrm{SP} 600125$ for $48 \mathrm{~h}$, each group had five replicates. Next, cells were incubated for $48 \mathrm{~h}$ in a cell incubator $\left(5 \% \mathrm{CO}_{2}, 37^{\circ} \mathrm{C}\right)$. A total of $\sim 10 \mu \mathrm{lCC}-8$ solution was added into each well and incubated at $37^{\circ} \mathrm{C}$ for $3 \mathrm{~h}$. The absorbance of the reaction solution at $450 \mathrm{~nm}$ was measured.

Cell apoptosis assay using flow cytometry. The cells were cultured in six-well plates $\left(1 \times 10^{6}\right.$ cells/well) and incubated for $24 \mathrm{~h}$. Next, the cells were treated with sCD40L and SP600125 and incubated for another $48 \mathrm{~h}$. The cells were then collected and centrifuged at $300 \mathrm{x}$ g for $3 \mathrm{~min}$ at $25^{\circ} \mathrm{C}$. Furthermore, the cells were washed twice with precooled phosphate-buffered saline (PBS), and subsequently, $1 \mathrm{ml} 1 \mathrm{x}$ binding buffer was used to resuspend the cells. Approximately $100 \mu \mathrm{l}$ cell resuspension solution was added to the new tubes, along with $5 \mu \mathrm{l}$ fluorescein isothiocyanate (FITC)-labelled Annexin V and $5 \mu \mathrm{PI}$ and incubated in the dark for $15 \mathrm{~min}$ at room temperature. Finally, $400 \mu 1 \mathrm{X}$ binding buffer was added, and the reaction solution was detected using a CytoFLEX flow cytometer (Beckman Coulter Inc.) with CytExpert v.2.0 software (Beckman Coulter Inc.).

Western blotting. The cells were treated with sCD40L and SP600125 and incubated for $48 \mathrm{~h}$, prior to being harvested and washed with precooled PBS. Radio immunoprecipitation assay lysate $[150 \mathrm{mM} \mathrm{NaCl}, 0.1 \%$ Triton $\mathrm{X}-100,0.5 \%$ sodium deoxycholate, $0.1 \%$ sodium dodecyl sulfate (SDS), $50 \mathrm{~mm}$ Tris $\mathrm{HCl}$ ( $\mathrm{pH}$ 8.0) and protease inhibitor] was used to extract the total protein, and was kept on ice and then centrifuged at 16,000 x g for $5 \mathrm{~min}$ at $4^{\circ} \mathrm{C}$. The protein concentrations were determined by conducting a bicinchoninic acid protein assay. For each sample, protein $(40 \mu \mathrm{g})$ were separated using $10 \%$ SDS-PAGE and then transferred onto polyvinylidene fluoride or polyvinylidene difluoride membranes. The membranes were blocked with $5 \%$ skimmed milk powder for $1 \mathrm{~h}$ at room temperature and then incubated overnight with protein antibodies BAX (1:1,000); Bcl-2 (1:1,000); ERK (1:1,000); p-ERK(1:2,000); p38(1:1,000); p-p38 (1:1,000); JNK(1:1,000); p-JNK (1:2,000); c-JUN $(1: 1,000)$ and GAPDH $(1: 1,000)$ at $4^{\circ} \mathrm{C}$. The membranes were washed with tris-buffered saline (TBST) three times. The second antibody solution goat anti-rabbit IgG $(\mathrm{H}+\mathrm{L})-\mathrm{HRP}$ (cat. no. SA009; Auragene) or goat anti-mouse IgG (H+L)-HRP (cat. no. SA001; Auragene) was added, and the membranes were incubated with the membranes at room temperature for $1 \mathrm{~h}$. Following washing with TBST three times, the proteins were examined using an enhanced chemiluminescent kit (Auragene).

Statistical analysis. SPSS 22.0 (IBM, Corp.) and GraphPad Prism 7.0 (GraphPad Software, Inc.) were used for data processing and statistical analysis. All experiments were performed three times. Data are expressed as the mean \pm standard deviation and were analyzed using analysis of variance, followed by the least significant difference post hoc test. $\mathrm{P}<0.05$ was considered to indicate a statistically significant difference.

\section{Results}

Exogenous sCD40L significantly inhibits the proliferation and promotes the apoptosis of lymphoma Raji and CA46 cells. The Raji and CA46 cells were initially treated with different concentrations of $\mathrm{sCD} 40 \mathrm{~L}(0,2,4,6,8$ and $10 \mu \mathrm{g} / \mathrm{ml})$ for $48 \mathrm{~h}$. Different concentrations of SCD40L significantly inhibited the viability of Raji and CA46 cells, and there were no notable differences in inhibitory effects among groups when the concentration of sCD40L was higher than $6 \mu \mathrm{g} / \mathrm{ml}$ (Fig. 1A). Therefore, $6 \mu \mathrm{g} / \mathrm{ml} \mathrm{sCD} 40 \mathrm{~L}$ was used to stimulate the Raji and CA46 cells for further study. To elucidate the apoptosis-inducing effect of sCD40L on Raji and CA46 cells, flow cytometry was used to detect the apoptosis of Raji and CA46 cells and treatment with $6 \mu \mathrm{g} / \mathrm{ml} \mathrm{sCD} 40 \mathrm{~L}$ was found to significantly increase the proportion of apoptosis (Fig. 1B and C). To further confirm the function of sCD40L in Raji and CA46 cells, the protein expression levels of the pro-apoptotic protein, $\mathrm{BAX}$, and the anti-apoptotic protein, $\mathrm{Bcl}-2$, were determined by conducting western blot analysis following treatment with $6 \mu \mathrm{g} / \mathrm{ml} \mathrm{sCD} 40 \mathrm{~L}$ for $48 \mathrm{~h}$. Compared with that in the untreated control, the stimulation of cells with SCD40L significantly upregulated the BAX protein expression levels and downregulated the Bcl-2 expression levels in Raji and CA46 cell lines (Fig. 1D). These results indicated that sCD40L significantly inhibited the cell proliferation and promoted the cell apoptosis of lymphoma Raji and CA46 cells.

Exogenous CD4OL activates the JNK signaling pathway. To further investigate the regulated mechanism of sCD40L in lymphoma Raji cells, western blotting was used to detect the protein expression levels of ERK, P38 and JNK, which 

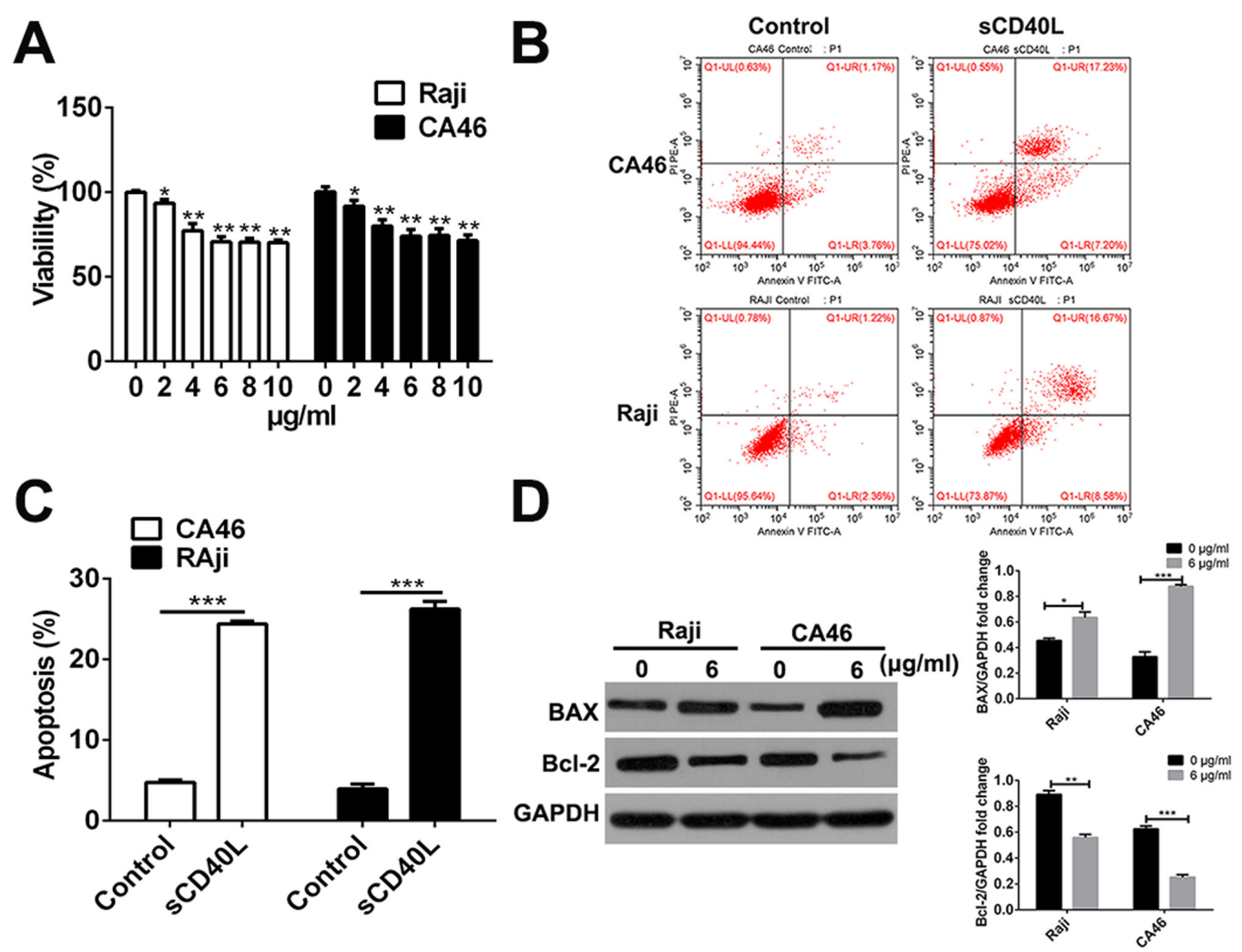

Figure 1. sCD40L inhibits the proliferation and promotes the apoptosis of lymphoma cells. (A) Raji and CA46 cells were treated with different concentrations of sCD40L for $48 \mathrm{~h}$, and a Cell Counting kit-8 assay was used to detect the viability of lymphoma cells. (B) Apoptosis of the lymphoma Raji and CA46 cells were confirmed via flow cytometry. (C) Statistical analysis of the apoptosis rate. (D) Western blotting was conducted to detect the protein expression levels of BAX and Bcl-2. All these assays were conducted three times. Data are expressed as the mean \pm standard deviation $(\mathrm{n}=3) .{ }^{*} \mathrm{P}<0.05,{ }^{* *} \mathrm{P}<0.01,{ }^{* * * *} \mathrm{P}<0.001$. sCD40L, soluble CD40 ligand.

were the classical pathway factors of the MAPK signaling pathway. As shown in Fig. 2, the expression levels of p-JNK in SCD40L-treated lymphoma cells increased significantly, while the P38 and ERK activity did not increase, suggesting that $\mathrm{SCD} 40 \mathrm{~L}$ activated the JNK signaling pathway, thereby promoting the apoptosis of lymphoma cells.

Inhibition of the JNK signaling pathway rescuing the sCD4OL-induced apoptosis of lymphoma cells. To further determine whether sCD40L induces apoptosis of lymphoma cells by activating the JNK signaling pathway, the lymphoma cells were treated with SP600125 $(10 \mu \mathrm{M})$, a specific inhibitor of the JNK signaling pathway. The results demonstrated that co-treatment with sCD40L and SP600125 significantly increased the cell viability (Fig. 3A) and decreased the cell apoptosis (Fig. 3B and C), compared with treatment with SCD40L alone, as detected by CCK-8 assay and flow cytometry, respectively. Western blotting was conducted and confirmed that SP600125 downregulated the expression of sCD40L-regulated BAX and upregulated the expression of sCD40L-regulated Bcl-2 (Fig. 3D). To further confirm the mechanism underlying the sCD40L-regulated activity through the JNK signaling pathway, the JNK, p-JNK and c-JUN expression levels were determined using western blot analysis and it was found that SP600125 significantly inhibited the sCD40L-regulated activity of JNK (Fig. 4A and B). These results indicated that SCD40L promotes lymphoma cell apoptosis through the activation of JNK signals.

\section{Discussion}

Lymphoma originates from malignant tumors of the lymphoid hematopoietic system, invading several tissues and organs outside the lymph nodes, including the bone marrow, causing abnormal bone marrow hematopoiesis $(23,24)$. Lymphomas can be classified into NHL and Hodgkin's lymphoma according to the tumor histopathology (25). NHL is a lymphatic malignant hyperplasia disease, with extremely strong heterogeneity. The incidence of NHL is high in China, accounting for $90 \%$ of all solid tumors of the immune system (26). However, the exact pathogenesis of NHL remains unknown.

CD40L (CD154) is a CD40 ligand that belongs to the TNF family (27). CD40L is expressed on the surface of normal cells and cancer cells, including bladder cancer (28), primary bone cancer (29), lung cancer and ovarian cancer cells (30). CD40L is associated with tumors, immunity and inflammation $(31,32)$. Additionally, CD40L is highly expressed in numerous types of cancer, but the tumorigenic role of CD40L remain controversial (33). Certain studies have suggested that CD40L has a tumorigenic effect $(7,34)$, but others have suggested that CD40L has an antitumor effect $(16,35,36)$. The CD40 signal has direct and indirect antitumor effects (35). CD40L has a significant inhibitory effect on AGS cells (36).

There are several shorter, stable, soluble forms of CD40L in addition to the full-length transmembrane protein. SCD40L retains the trimeric structure of the full-length protein and its biological functions (37). The sCD40L was able to bind and 

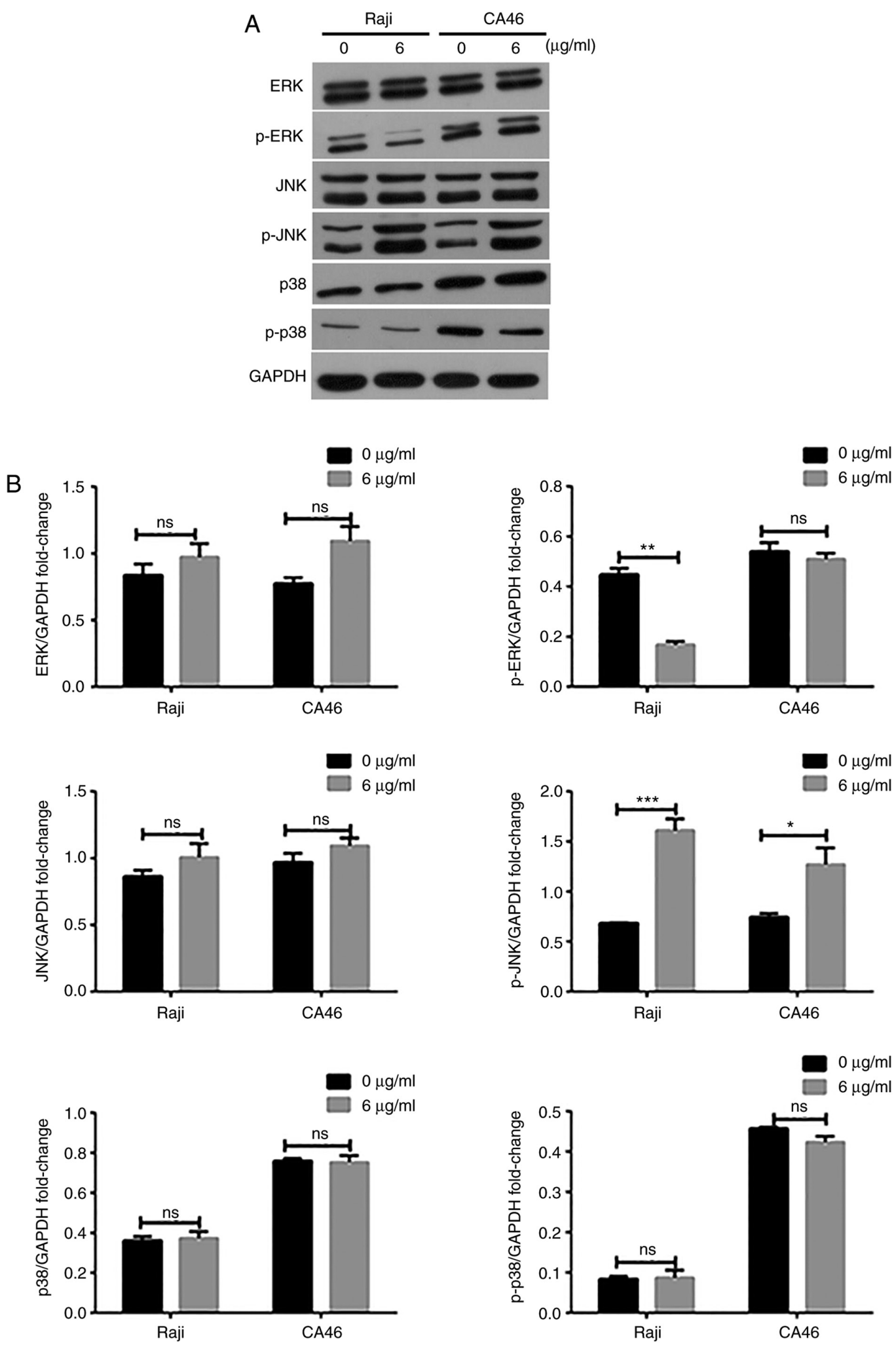

Figure 2. JNK activity is regulated by sCD40L in lymphoma Raji and CA46 cells. (A) Western blotting was used to detect the protein expression levels of ERK, p-ERK, JNK p-JNK, p38 and p-p38. (B) Statistical analysis of western blot analysis. All these assays were conducted three times. Data are expressed as the mean \pm standard deviation $(\mathrm{n}=3)$. ${ }^{*} \mathrm{P}<0.05,{ }^{* * *} \mathrm{P}<0.01,{ }^{* * * *} \mathrm{P}<0.001$. sCD 40L, soluble CD40 ligand; p-ERK, phosphorylated ERK; p-JNK, phosphorylated JNK; p-p38, phosphorylated p38.

internalize into B cells that expressed the CD40 receptor and specifically and efficiently induced apoptotic death (38). In the 1990, MacDonald et al (39) reported that trimeric sCD40L was able to inhibit apoptosis induced by the combination of agonists to a certain degree, but such rescue proved to be short-lived.

Therefore, to further study the influence of CD40L on lymphoma cells, the effect of $\mathrm{SCD} 40 \mathrm{~L}$ on the proliferation 

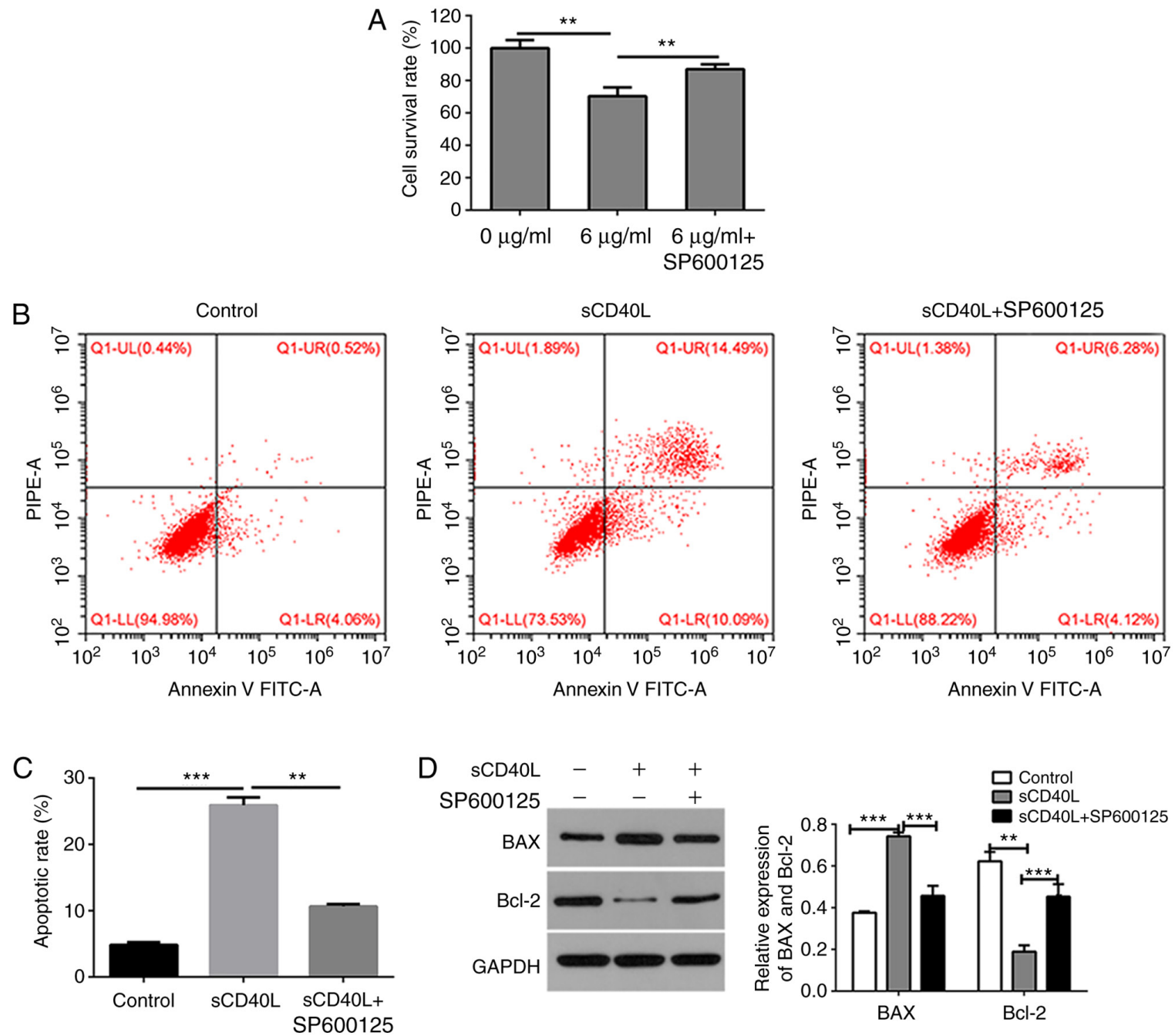

Figure 3. sCD40L promotes the apoptosis of Raji cells, but SP600125 inhibits its effect. (A) The cell viability was determined using the Cell Counting kit-8. (B) The apoptosis of the Raji cells was confirmed by flow cytometry. (C) Statistical analysis of the apoptotic rate. (D) Western blot analysis was conducted to detect the expression of BAX and Bcl-2. All these assays were conducted three times. Data are expressed as the mean \pm standard deviation $(\mathrm{n}=3)$. ${ }^{* *} \mathrm{P}<0.01$, ${ }^{* * *} \mathrm{P}<0.001$. sCD40L, soluble CD40 ligand.

A

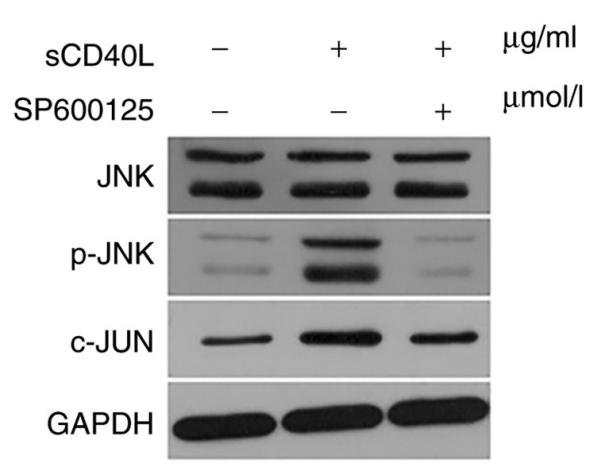

B

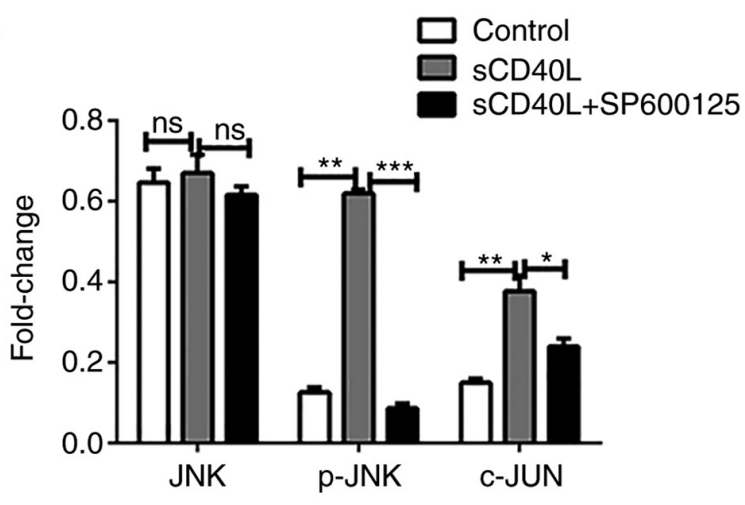

Figure 4. SCD40L promotes the apoptosis of Raji cells by regulating the JNK pathway. (A) Western blot analysis was conducted to detect the expression of JNK, p-JNK and c-JUN. (B) Statistical analysis of western blotting. All these assays were conducted three times. Data are expressed as mean \pm standard deviation ( $\mathrm{n}=3) .{ }^{*} \mathrm{P}<0.05,{ }^{* *} \mathrm{P}<0.01,{ }^{* * * *} \mathrm{P}<0.001$. sCD40L, soluble CD40 ligand; p-JNK, phosphorylated JNK.

and apoptosis in lymphoma cells was investigated. The results of the present study demonstrated that the proliferation of Raji and CA46 cells was significantly inhibited by different concentrations of sCD40L investigated by CCK-8 assays. Our previous study demonstrated that the proliferation inhibition rate of cells treated with different concentrations of sCD40L after 48 and $72 \mathrm{~h}$ was higher than that at $24 \mathrm{~h}(40)$; therefore, $48 \mathrm{~h}$ was selected as an incubation time for the CCK-8 assay. 
The results demonstrated that as the concentration is increased, the inhibitory ability became more evident, and when the sCD40L concentration was higher than $6 \mu \mathrm{g} / \mathrm{ml}$, the inhibitory effects exhibited a steady trend. The follow-up studies were conducted using flow cytometry, and it was found that $6 \mu \mathrm{g} / \mathrm{ml}$ sCD40L treatment significantly increased the proportion of apoptosis. Although quantitative polymerase chain reaction (qPCR) was not used to detect the expression of the apoptotic factor, BAX, and the anti-apoptotic factor, Bcl-2, in the present study, the expression of Bcl-2 and BAX were detected by western blot analysis, and the results demonstrated that the expression of BAX increased and the expression of $\mathrm{Bcl}-2$ decreased following Raji and CA46 cells being treated with $6 \mu \mathrm{g} / \mathrm{ml} \mathrm{sCD} 40 \mathrm{~L}$. The expression of BAX and Bcl-2 should be detected by qPCR in the future. Taken together, these results suggested that SCD40L inhibited the cell proliferation and induced the apoptosis of lymphoma Raji and CA46 cell lines.

The present study verified that SCD40L inhibits the growth of lymphoma, but the relative molecular mechanism of sCD40L in lymphoma cells remained uncertain. The earliest detectable events following CD40 activation were the activation of protein tyrosine kinases, phosphoinositide-3 kinase (PI3k) and phospholipase $\mathrm{Cg} 2$; the activation of cAMP modulated both positive and negative CD40-induced responses (41). CD40L mediated the alternative NFKB signaling pathway in mantle cell lymphoma to induce resistance to BCR inhibitors (42). Recent studies have concentrated on the involvement of JNK/SAPK, p38 MAPK and ERK signaling pathways (4,43-46). However, the conclusions of several associated studies were controversial, and general conclusions should be interpreted with caution because these studies often used different cellular models.

Considering the important role of the MAPK signaling pathway in lymphomas $(47,48)$ and that the JNK signaling pathway is a well-known pathway that induces cell apoptosis (49), the present study investigated the molecular mechanism by which sCD40L induces apoptosis in lymphoma cell lines. The results demonstrated that the phosphorylation level of JNK was significantly increased, while the phosphorylation level of p38 and ERK did not change following Raji and CA46 cells being treated with sCD40L. Therefore, sCD40L may significantly induce the activation of the JNK signaling pathway but not p38 signaling pathway or ERK signaling pathway. Therefore, the data indicated that SCD40L induced the apoptosis of lymphoma Raji and CA46 cell lines through the JNK signaling pathway. Furthermore, the results showed that SCD40L has the same effect on the apoptosis of Raji and CA46 cells. Therefore, in order to verify these results, the Raji cell line was selected for further research. SP600125, an inhibitor of JNK signaling pathway, was used to treat Raji cells, and the results demonstrated that SP600125 may promote the proliferation and inhibited the apoptosis of Raji cells, which were induced by sCD40. Although the study also obtained a similar conclusion that $\mathrm{SCD} 40 \mathrm{~L}$ induced the apoptosis of Raji through the JNK signaling pathway in vitro, in vivo experiments need to be performed in future studies.

Although the present study confirmed that sCD40L may inhibit the proliferation and induce the apoptosis of Raji and CA46 cell lines, CD40 expression in Raji and CA46 cells was not investigated. This is a limitation of the present study, which will be considered in future studies.
In summary, sCD40L inhibited the proliferation and promoted the apoptosis of the lymphoma cell lines. Additionally, sCD40L inhibited the growth of lymphoma Raji and CA46 cell lines and induced apoptosis by activating the JNK signaling pathway. These results suggested that SCD40L may be a potential therapeutic drug for suppressing NHL.

\section{Acknowledgements}

Not applicable.

\section{Funding}

The present study was supported by funds from the Joint Fund of Science and Technology Department of Guizhou Province (Qiankehe LH [2017]7092).

\section{Availability of data and materials}

All data generated or analyzed during this study are included in this published article.

\section{Authors' contributions}

ZF designed the study, analyzed data, performed experiments and wrote the manuscript. JW collected funding, researched the literature, managed the project and collected the data. Both authors read and approved the final manuscript.

\section{Ethics approval and consent to participate}

Not applicable.

\section{Patient consent for publication}

Not applicable.

\section{Competing interests}

The authors declare that they have no competing interests.

\section{References}

1. Jiang M, Bennani NN and Feldman AL: Lymphoma classification update: T-cell lymphomas, Hodgkin lymphomas, and histiocytic/dendritic cell neoplasms. Expert Rev Hematol 10: 239-249, 2017.

2. Pratap S and Scordino TS: Molecular and cellular genetics of non-Hodgkin lymphoma: Diagnostic and prognostic implications. Exp Mol Pathol 106: 44-51, 2019.

3. Muto R, Miyoshi H, Sato K, Furuta T, Muta H, Kawamoto K, Yanagida E, Yamada K and Ohshima K: Epidemiology and secular trends of malignant lymphoma in Japan: Analysis of 9426 cases according to the world health organization classification. Cancer Med 7: 5843-5858, 2018.

4. van Kooten C and Banchereau J: CD40-CD40 ligand. J Leukoc Biol 67: 2-17, 2000.

5. Carbone A, Gloghini A, Zagonel V, Aldinucci D, Gattei V, Degan M, Improta S, Sorio R, Monfardini S and Pinto A: The expression of CD26 and CD40 ligand is mutually exclusive in human T-cell non-Hodgkin's lymphomas/leukemias. Blood 86: 4617-4626, 1995.

6. Hussain SA, Ganesan R, Hiller L, Murray PG, el-Magraby MM, Young L and James ND: Proapoptotic genes BAX and CD40L are predictors of survival in transitional cell carcinoma of the bladder. Br J Cancer 88: 586-592, 2003. 
7. Li R, Chen WC, Pang XQ, Hua C, Li L and Zhang XG: Expression of CD40 and CD40L in gastric cancer tissue and its clinical significance. Int J Mol Sci 10: 3900-3917, 2009.

8. Mach F, Schönbeck U, Sukhova GK, Atkinson E and Libby P: Reduction of atherosclerosis in mice by inhibition of CD40 signaling. Nature 394: 200-203, 1998.

9. Xu W, Li Y, Yuan WW, Yin Y, Song WW, Wang Y, Huang QQ, Zhao WH and Wu JQ: Membrane-Bound CD40L promotes senescence and initiates senescence-associated secretory phenotype via NF- $\kappa \mathrm{B}$ activation in lung adenocarcinoma. Cell Physiol Biochem 48: 1793-1803, 2018.

10. Buhmann R, Nolte A, Westhaus D, Emmerich B and Hallek M: CD40-activated B-cell chronic lymphocytic leukemia cells for tumor immunotherapy: Stimulation of allogeneic versus autologous T cells generates different types of effector cells. Blood 93: 1992-2002, 1999.

11. Tsubata $\mathrm{T}, \mathrm{Wu} \mathrm{J}$ and Honjo T: B-cell apoptosis induced by antigen receptor crosslinking is blocked by a T-cell signal through CD 40 . Nature 364: 645-648, 1993.

12. van Kooten C, Gaillard C, Galizzi JP, Hermann P, Fossiez F, Banchereau J and Blanchard D: B cells regulate expression of CD40 ligand on activated T cells by lowering the mRNA level and through the release of soluble CD40. Eur J Immunol 24: 787-792, 1994.

13. Chatzigeorgiou A, Seijkens T, Zarzycka B, Engel D, Poggi M, van den Berg S, van den Berg S, Soehnlein O, Winkels $H$ Beckers L, et al: Blocking CD40-TRAF6 signaling is a therapeutic target in obesity-associated insulin resistance. Proc Natl Acad Sci USA 111: 2686-2691, 2014.

14. Cantwell M, Hua T, Pappas J and Kipps TJ: Acquired CD40-ligand deficiency in chronic lymphocytic leukemia. Nat Med 3: 984-989, 1997.

15. Feng Z and Chen Q: Raised CD40L expression attenuates drug resistance in adriamycin-resistant THP-1 cells. Exp Ther Med 19: 2188-2194, 2020

16. Pang X, Zhang L, Wu J, Ma C, Mu C, Zhang G and Chen W: Expression of CD40/CD40L in colon cancer, and its effect on proliferation and apoptosis of SW48 colon cancer cells. J BUON 22: 894-899, 2017.

17. Qin L, Qiu H, Zhang M, Zhang F, Yang H, Yang L, Jia L, Qin K, Jia L, Dou X, et al: Soluble CD40 ligands sensitize the epithelial ovarian cancer cells to cisplatin treatment. Biomed Pharmacother 79: 166-175, 2016.

18. Georgopoulos NT, Steele LP, Thomson MJ, Selby PJ, Southgate J and Trejdosiewicz LK: A novel mechanism of CD40-induced apoptosis of carcinoma cells involving TRAF3 and JNK/AP-1 activation. Cell Death Differ 13: 1789-1801, 2006

19. Ara A, Ahmed KA and Xiang J: Multiple effects of CD40-CD40L axis in immunity against infection and cancer. Immunotargets Ther 7: 55-61, 2018.

20. Deng N, Chen Q, Guo X, Liu L, Chen S, Wang A, Li R, Huang Y, Ding X, Yu H, et al: Blockade of CD40L inhibits immunogenic maturation of lung dendritic cells: Implications for the role of lung iNKT cells in mouse models of asthma. Mol Immunol 121: 167-185, 2020

21. Lima PMA, Torres LC, Martins MR, da Matta MC, Lima JTO, de Mello MJG, da Silva LM, Cintra EB Jr, Lira CCR da Fonte EJA and Forones NM: Soluble levels of sCD40L and s4-1BB are associated with a poor prognosis in elderly patients with colorectal cancer. J Surg Oncol 121: 901-905, 2020.

22. Adem J, Eray M, Eeva J, Nuutinen U and Pelkonen J: RIP1 has a role in CD40-mediated apoptosis in human follicular lymphoma cells. Immunobiology 222: 998-1003, 2017.

23. Armitage JO, Gascoyne RD, Lunning MA and Cavalli F: Non-Hodgkin lymphoma. Lancet 390: 298-310, 2017.

24. Jeudy J, Burke AP and Frazier AA: Cardiac lymphoma. Radiol Clin North Am 54: 689-710, 2016.

25. Mugnaini EN and Ghosh N: Lymphoma. Prim Care 43: 661-675, 2016.

26. Bowzyk Al-Naeeb A, Ajithkumar T, Behan S and Hodson DJ: Non-Hodgkin lymphoma. BMJ 362: k3204, 2018.

27. Seigner J, Basilio J, Resch U and de Martin R: CD40L and TNF both activate the classical NF- $\mathrm{BB}$ pathway, which is not required for the CD40L induced alternative pathway in endothelial cells Biochem Biophys Res Commun 495: 1389-1394, 2018.

28. Xu W, Li Y, Wang X, Wang C, Zhao W and Wu J: Anti-tumor activity of gene transfer of the membrane-stable CD40L mutant into lung cancer cells. Int J Oncol 37: 935-941, 2010.

29. Solooki S, Khozaei A, Shamsdin SA, Emami MJ and Khademolhosseini F: sCD30 and sCD40L detection in patients with osteosarcoma, chondrosarcoma and Ewing sarcoma. Iran J Immunol 10: 229-237, 2013.
30. Gallagher NJ, Eliopoulos AG, Agathangelo A, Oates J, Crocker J and Young LS: CD40 activation in epithelial ovarian carcinoma cells modulates growth, apoptosis, and cytokine secretion. Mol Pathol 55: 110-120, 2002

31. Hausding M,Jurk K, Daub S, Kröller-Schön S,Stein J, Schwenk M, Oelze M, Mikhed Y, Kerahrodi JG, Kossmann S, et al: CD40L contributes to angiotensin II-induced pro-thrombotic state, vascular inflammation, oxidative stress and endothelial dysfunction. Basic Res Cardiol 108: 386, 2013.

32. Walker PR and Migliorini D: The CD40/CD40L axis in glioma progression and therapy. Neurooncology 17: 1428-1430, 2015.

33. Hassan GS, Stagg J and Mourad W: Role of CD154 in cancer pathogenesis and immunotherapy. Cancer Treat Rev 41: 431-440, 2015.

34. Pan W, Gong J, Yang C, Feng R, Guo F, Sun Y and Chen H: Peripheral blood CD40-CD40L expression in human breast cancer. Ir J Med 182: 719-721, 2013.

35. Ottaiano A, Pisano C, De Chiara A,Ascierto PA, Botti G, Barletta E, Apice $\mathrm{G}$, Gridelli C and Iaffaioli VR: CD40 activation as potential tool in malignant neoplasms. Tumori 88: 361-366, 2002.

36. Qi CJ, Qian KQ, Ning YL, Ma HB, Wang SZ and Zhang XG: Ligation or cross-linking of CD40 has different effects on AGS gastric cancer cells. Cell Immunol 259: 135-140, 2009.

37. Mazzei GJ, Edgerton MD, Losberger C, Lecoanet-Henchoz S, Graber P, Durandy A, Gauchat JF, Bernard A, Allet B and Bonnefoy JY: Recombinant soluble trimeric CD40 ligand is biologically active. J Biol Chem 270: 7025-7028, 1995.

38. Kedar R, Sabag O, Licthenstein M and Lorberboum-Galski H: Soluble CD40 ligand (sCD40L) provides a new delivery system for targeted treatment: SCD40L-caspase 3 chimeric protein for treating B-cell malignancies. Cancer 118: 6089-6104, 2012.

39. MacDonald I, Wang H, Grand R, Armitage RJ, Fanslow WC, Gregory CD and Gordon J: Transforming growth factor-beta 1 cooperates with anti-immunoglobulin for the induction of apoptosis in group I (biopsy-like) Burkitt lymphoma cell lines. Blood 87: 1147-1154, 1996.

40. Mingqiang R and Xinging M: Effects of soluble CD40 ligand on proliferation and apoptosis of Human B cell lymphoma cell line BJAB and its mechanism. Shandong Med J 56: 16-19, 2016 (In Chinese).

41. Goldstein MD, Cochrane A and Watts TH: Cyclic-AMP modulates downstream events in CD40-mediated signal transduction, but inhibition of protein kinase A has no direct effect on CD40 signaling. J Immunol 159: 5871-5880, 1997.

42. Rauert-Wunderlich $H$, Rudelius M, Berberich I and Rosenwald A CD40L mediated alternative $\mathrm{NF}$ BB-signaling induces resistance to BCR-inhibitors in patients with mantle cell lymphoma. Cell Death Dis 9: 86, 2018.

43. Berberich I, Shu G, Siebelt F, Woodgett JR, Kyriakis JM and Clark EA: Cross-linking CD40 on B cells preferentially induces stress-activated protein kinases rather than mitogen-activated protein kinases. EMBO J 15: 92-101, 1996.

44. Grammer AC, Swantek JL, McFarland RD, Miura Y, Geppert T and Lipsky PE: TNF receptor-associated factor-3 signaling mediates activation of p38 and Jun $\mathrm{N}$-terminal kinase, cytokine secretion, and Ig production following ligation of CD40 on human B cells. J Immunol 161: 1183-1193, 1998.

45. Mintz MA, Felce JH, Chou MY, Mayya V, Xu Y, Shui JW, An J, Li Z, Marson A, Okada T, et al: The HVEM-BTLA axis restrains $T$ cell help to germinal center $B$ cells and functions as a cell-extrinsic suppressor in lymphomagenesis. Immunity 51: 310-323 e317, 2019.

46. Purkerson JM and Parker DC: Differential coupling of membrane Ig and CD40 to the extracellularly regulated kinase signaling pathway. J Immunol 160: 2121-2129, 1998.

47. Huang Y,Zou Y, Lin L, Ma X and Zheng R: miR101 regulates the cell proliferation and apoptosis in diffuse large Bcell lymphoma by targeting MEK1 via regulation of the ERK/MAPK signaling pathway. Oncol Rep 41: 377-386, 2019.

48. Moriguchi M, Watanabe T, Kadota A and Fujimuro M: Capsaicin induces apoptosis in KSHV-positive primary effusion lymphoma by suppressing ERK and p38 MAPK signaling and IL-6 expression. Front Oncol 9: 83, 2019.

49. Akhter R, Sanphui P, Das H, Saha P and Biswas SC: The regulation of p53 up-regulated modulator of apoptosis by JNK/c-Jun pathway in $\beta$-amyloid-induced neuron death. J Neurochemistry 134: 1091-1103, 2015.

This work is licensed under a Creative Commons Attribution-NonCommercial-NoDerivatives 4.0 International (CC BY-NC-ND 4.0) License. 